Document downloaded from:

http://hdl.handle.net/10251/171327

This paper must be cited as:

Valero-Marco, J.; Lehrheuer, B.; López, JJ.; Pischinger, S. (2021). Study of the engine configuration effect on the maximum achievable load in CAl using water injection. International Journal of Engine Research. 22(9):2945-2957.

https://doi.org/10.1177/1468087420960858

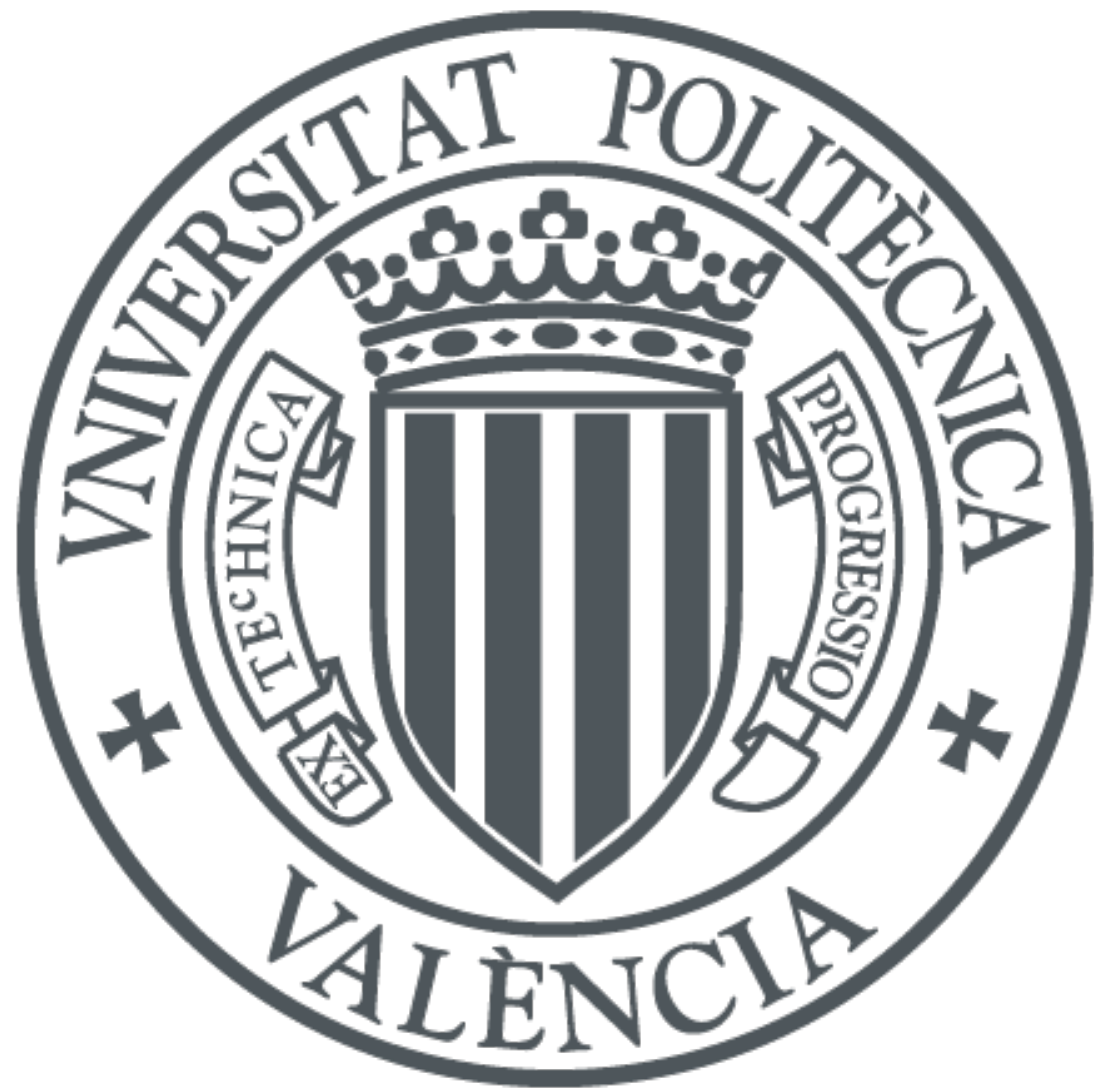

The final publication is available at

https://doi.org/10.1177/1468087420960858

Copyright SAGE Publications

Additional Information

This is the author's version of a work that was accepted for publication in International Journal of Engine Research. Changes resulting from the publishing process, such as peer review, editing, corrections, structural formatting, and other quality control mechanisms may not be reflected in this document. Changes may have been made to this work since it was submitted for publication. A definitive version was subsequently published as https://doi.org/10.1177/1468087420960858. 


\title{
Study of the engine configuration effect \\ on the maximum achievable load in CAI \\ using water injection
}

Journal Title

$X X(X): 1-17$

(C)The Author(s) 2020

Reprints and permission:

sagepub.co.uk/journalsPermissions.nav

DOI: $10.1177 /$ ToBeAssigned

www.sagepub.com/

(9)SAGE

\section{J. Valero-Marco ${ }^{1}$, B. Lehrheuer ${ }^{2}$, Dr. J. J. López ${ }^{1}$ and Dr. S. Pischinger ${ }^{2}$}

\begin{abstract}
The approach of this research is to enlarge the knowledge about the methodologies to increase the maximum achievable load degree in the context of gasoline CAl engines. This work is the continuation of a previous work related to the study of the water injection effect on combustion, where this strategy was approached. The operating strategies to introduce the water and the interconnected settings were deeply analyzed in order to optimize combustion and to evaluate its potential to increase the maximum load degree when operating in CAI. During these initial tests, the engine was configured to enhance the mixture autoignition. The compression ratio was high compared to a standard gasoline engine, and suitable fuel injection strategies were selected based on previous studies from the authors to maximize the reactivity of the mixture, and get a stable CAI operation.

Once water injection proved to provide encouraging results, the next step dealt in this work, was to go deeper and explore its effects when the engine configuration is more similar to a conventional gasoline engine, trying to get CAI combustion closer to production engines. This means, mainly, lower compression ratios and different fuel injection strategies, which hinders CAI operation. Finally, since all the previous works were performed at constant engine speed, the engine speed was also modified in order to see the applicability of the defined strategies to operate under CAI conditions at other operating conditions.

The results obtained show that all these modifications are compatible with CAI operation: the required compression ratio can be reduced, in some cases the injection strategies can be simplified, and the increase of the engine speed leads to better conditions for CAl combustion. Thanks to the analysis of all this data, the different key parameters to manage this combustion mode are identified and shown in the paper.
\end{abstract}

\section{Keywords}

CAI, Controlled autoignition, $\mathrm{HCCl}$, gasoline engines, four stroke, water injection, wider operating range

\section{Introduction}

The general trends on the transport sector are currently moving to a sustainable energetic model, where clean engine fuels, renewable energy sources and new combustion technologies are the hot topic of extensive research. These

${ }^{1}$ CMT-Motores Térmicos, Universitat Politècnica de València, Spain

Camino de Vera, s/n. 46022 Valencia, SPAIN

2 Institute for Combustion Engines VKA

RWTH Aachen University

Forckenbeckstr. 4, Aachen, Germany 
trends have been accelerated by the increasing stringency of the pollutant emissions regulations, leading to a scenario where the vehicle-out pollutant emissions and the fuel efficiency must be improved.

The gasoline Controlled Auto-Ignition (CAI) combustion, which can be found sometimes also referred as Homogeneous Charge Compression Ignition (HCCI), is not a new invention $^{1 ; 2}$, but it has recently re-emerged as an interesting evolution of the combustion process for gasoline engines. This different concept has a high interest due to a high efficiency and very low particulate and $\mathrm{NO}_{x}$ emissions compared to the current Spark Ignition (SI) or Compression Ignition $(\mathrm{CI})$ combustion processes. Unlike the traditional gasoline engines using a spark plug to start the combustion of the fuel-air mixture, this combustion process is mainly governed by the chemical kinetics ${ }^{3 ; 4}$ of the in-cylinder mixture: through the control of the thermodynamic conditions (pressure and temperature) and the chemical conditions (charge composition) a controlled autoignition process can be achieved ${ }^{5}$.

In comparison to SI systems, the CAI combustion is more repetitive, presenting lower variation of the cycle-tocycle IMEP (Indicated Mean Effective Pressure), and then providing much better combustion stability. Besides, this different combustion mode reaches lower local temperatures during the combustion event. This results in a noticeable improvement of the combustion development, the pollutant emissions are reduced and the fuel consumption is also reduced in comparison to SI flame front developed combustion $^{6}$.

However, there are several troubles to deal with:

First, the pressure gradients generated by this combustion can be very high since the combustion rates are significantly higher, especially when the load degree is increased ${ }^{5}$. These pressure gradients can damage the mechanical elements of the engine.
And, second, since there is not a specific element to initiate the combustion of the charge, the ignition process has to be started through the control of the mixture reactivity ${ }^{7}$, which is very sensitive to the variations on the operating configuration of the engine, and even to combustion instabilities. Under these circumstances, since the combustion phasing is not controlled by the spark, the combustion process can be over-advanced, delayed, or even extinguished depending on the reactivity of the charge in each moment. This "reactivity dependence" constrains the possibility to operate in CAI conditions throughout all the engine map ${ }^{5}$.

This process which was initially achieved in two stroke engines $^{8}$, has led to several works in order to get CAI systems also on four-stroke engines through different strategies: e.g. increase of the intake temperatures, increase of the compression ratio, hot residual gases trapping, etc. ${ }^{9-11}$. All these strategies have proven to be good ways to achieve CAI combustion, and have been shown to be an encouraging improvement for the future gasoline engines on the roads. But another problem to overcome is the limited operation range of this combustion mode, currently only achievable at low load conditions due to its high pressure gradients and a higher knocking tendency when the load demand is increased, as well as the raise of combustion instabilities at low loads due to the poor reactivity of the mixture.

Focusing on the increase of the maximum achievable load degree for automotive applications, several approaches have been reviewed. Some of these approaches are well known, like EGR introduction ${ }^{12 ; 13}$, charge stratification ${ }^{14}$, whereas others more specialized for CAI combustion, as for instance:

\section{Corresponding author:}

Dr. J. Javier López

CMT-Motores Térmicos, Universitat Politècnica de València, Spain

Camino de Vera, s/n. 46022 Valencia, SPAIN

Tel: +34 963879 232. Fax: +34963877 659

Email: jolosan3@mot.upv.es 
fuel injection adapted strategies, valve train modifications or fuel composition adaptations ${ }^{15-19}$.

In this work, the selected approach to overcome these limitations is based on the introduction of reaction suppressors within the charge in order to get a better control of the charge reactivity, thus optimizing the combustion process.

If the literature is reviewed, some works can be found dealing with similar topics ${ }^{20-23}$, all of them introducing different reactivity suppressors mixed with the fuel (either directly mixed with the fuel or injected separately). More precisely, the use of water has been a focus of interest in CAI or HCCI combustion ${ }^{24 ; 25}$, since the cooling effect caused by its high specific heat capacity can be used to control the timing of the autoignition event, to optimize the combustion position, and to slow down the excessive combustion rates when necessary. But not many works puting together CAI combustion and water injection are available in the literature. However, if a look is taken to water injection application in SI engines, it can be seen that this is a really hot topic of research nowadays. Some relevant and recent works are: Golzari, R. et al. ${ }^{26}$, Hoppe, F. et al. ${ }^{27}$, Li, A. ${ }^{28}$ or Schmitt, S. et al. ${ }^{29}$, just to cite a few examples.

After seeing its potential, the water has been selected as the reaction suppressor in the current research. The purpose of the water addition is to better control the mixture reactivity thanks to its high heat capacity which will be used to reduce the in-cylinder charge temperatures, which are assumed to be directly related to the mixture reactivity, and therefore to the excessive pressure rise rates when the load degree is increased. This excessive reactivity is the main responsible for the knock intensity enhancement in CAI combustion. In a previous work $^{30}$, water injection has proven to be a promising solution to enlarge the operating load range. At that research, the engine configuration was modified to enhance CAI operation (a high compression ratio was used, as well as some specific CAI operating strategies, to enhance the mixture reactivity: trapping of hot residual gases -with negative valve overlap, NVO- and specific fuel injection strategies).

Now, the main objective of the present research is to test different engine configurations (compression ratio modification, different injection strategies, and different engine speeds), most of them closer to standard SI engines, so as to check the feasibility to work under CAI combustion at different conditions. Additionally, the approach of the CAI operation to different engine configurations and the necessary operation strategies to get a stable and efficient combustion will be also studied.

Finally, the paper structure is going to be as follows:

- Experimental Facilities and Methodology: the experimental setup is described, as well as the followed test plan and the details of the testing methodology.

- Results and Discussion:

- Water injection in CAI conditions.

- Influence of the compression ratio and fuel injection strategy.

- Engine speed modification.

- Conclusions: the obtained results are synthesized and the most important goals during the current research are remarked.

\section{Experimental facilities and methodology}

This section gives the required information to figure out and support the results presented through the paper by the explanation of the different parts of the facility, the tests procedure and the analysis of the results.

\section{Experimental facilities}

For this work, a single cylinder four-stroke gasoline engine, built to operate as a SI, has been used to develop, on an experimental basis, the different tests. This engine has been configured in order to get a CAI combustion process by 
changing the actuation of the intake and exhaust valves, modifying the compression ratio and reconfiguring the fuel injection strategies. Besides all these modifications, a direct water injection system has been added as well.

\section{The engine}

The engine will be referred as GCAI engine (Gasoline Controlled Auto-Ignition engine). Table 1 shows its main specifications, which will be briefly described in the following lines.

The cylinder head of this engine has been arranged to hold the referred two injectors and the spark plug, as shown in Figure 1. In the figure, the central injector is for fuel, whereas the lateral one is for water, and the chosen operating pressure of the two injection systems allows to inject both, fuel and water at any crank angle position. This fact helps to design the injection strategies without cylinder pressure limitations. And regarding the spark plug, this one is necessary to start the combustion when the engine is cold, otherwise it is impossible to promote the autoignition of the charge, and also, to operate the engine as a SI when it will be required.

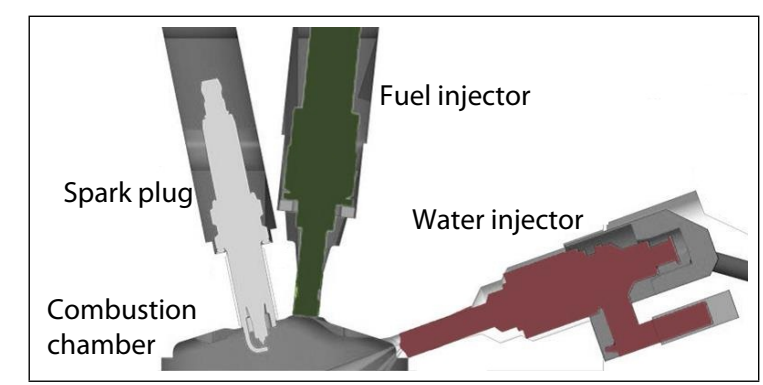

Figure 1. Engine head configuration.

\section{Modification of the compression ratio}

For the engine compression ratio modification, the piston has been replaced by a piston with an equivalent shape, but with a higher separation between the piston surface in contact with the combustion chamber and the link with the connecting rod. By this way the bore and stroke of the engine are maintained, and the clearance between the piston and the cylinder head is reduced.

\section{The valve train}

This system follows a different strategy compared to the one used for SI operation. Now the valves are controlled so as to retain a part of the exhaust gases from the previous cycle in the cylinder. These hot exhaust gases are used to increase the mixture reactivity and make possible the controlled autoignition of the charge. Now the camshafts have a reduced valve lift (Figure 2), compared to the previous SI configuration, and they also have a Variable Valve Timing (VVT) system attached to each camshaft.

The Exhaust Valve Closing (EVC) and Intake Valve Opening (IVO) angles are significantly different compared to a SI engine. Now, the EVC takes place before Top Dead Center (TDC) and the IVO after TDC. By this way an additional period is created surrounding the TDC in between the exhaust and the intake strokes where the cylinder is closed with hot residual gases which have not been expelled during the exhaust stroke. This strategy allows keeping inside the cylinder a variable rate of hot residual gases, being recompressed during the end of the exhaust stroke, and then combined with fresh gases when the intake valves are opened.

The camshafts position is controlled through the distance between the EVC and the IVO (EVC-IVO). This distance (in ${ }^{\circ} \mathrm{CA}$ ) is named Negative Valve Overlap (NVO). It is important to point out that the actuation of the VVT systems is symetrical from the TDC (i.e. if the EVC has been advanced $5^{\circ} \mathrm{CA}$, therefore the IVC is also delayed $5^{\circ} \mathrm{CA}$ ), so as to simplify and reduce the amount of variables to control the engine. If the resulting NVO absolute value is increased, the closure of the exhaust valve is advanced, and consequently the residual rates are higher. And, on the other hand, the decrease of the absolute value of NVO implies smaller negative overlaps, and thus smaller residual rates.

\section{Air supply}

The engine is operated with high lambda values in order 


\begin{tabular}{|l|l|}
\hline $\begin{array}{l}\text { Displacement/ Bore/ } \\
\text { Stroke: }\end{array}$ & $400 \mathrm{cc} / 75 \mathrm{~mm} / 90.5 \mathrm{~mm}$ \\
\hline Compression ratio: & $14.7[-]$ and 13.5 [-] \\
\hline Valve train: & Variable valve timing installed in both camshafts. \\
\hline Fuel metering: & 150 bar nominal pressure DI with solenoid multi-hole (6) injector. \\
\hline Water metering: & 100 bar nominal pressure DI with solenoid multi-hole (5) injector. \\
\hline Intake: & $\begin{array}{l}\text { Roots external compressor + heating system, to control pressure and } \\
\text { temperature. }\end{array}$ \\
\hline Exhaust: & Back-pressure electro-pneumatic valve for pressure regulation. \\
\hline Fuel: & Commercial 95 RON gasoline with 10\% of ethanol in volume. \\
\hline
\end{tabular}

Table 1. Engine specifications

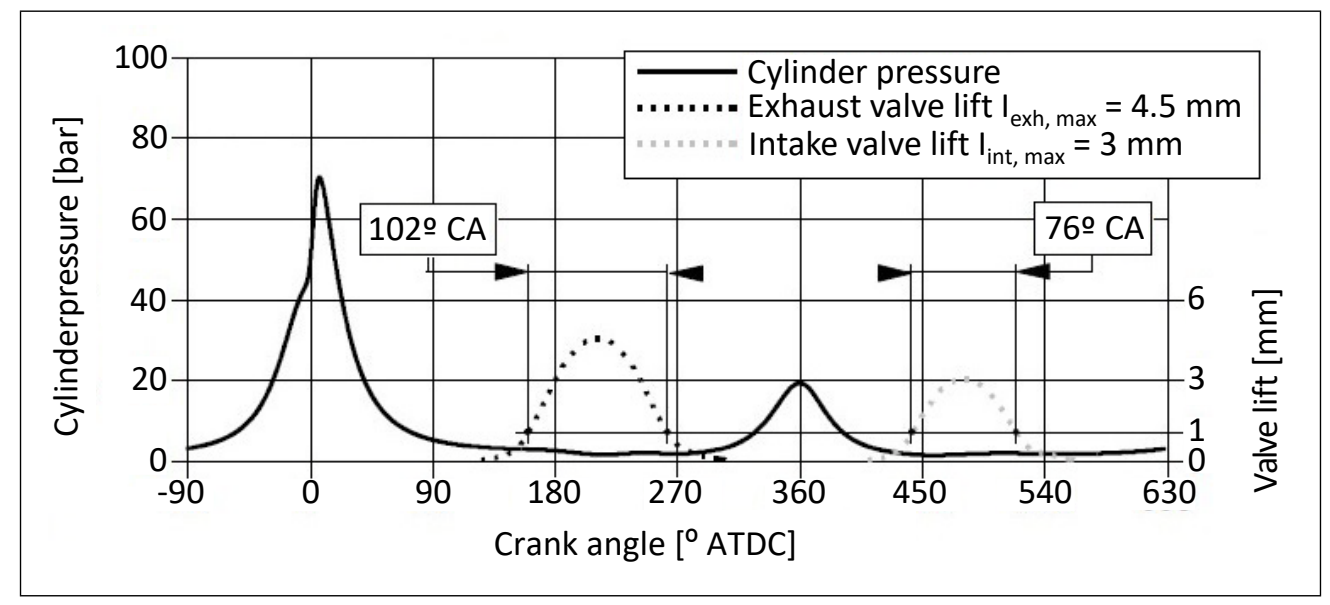

Figure 2. Configuration of the intake and exhaust valve lifts.

to achieve higher efficiency values. But due to the valve train configurations for CAI operation, the engine is now significantly less permeable (delay of the intake opening and higher in-cylinder pressures at this moment), and therefore the pressure at the intake must be increased to maintain the whole load degree range and the possibility to decrease the lambda. Taking this situation, the exhaust pressure is going to be set to the same value as the intake, with the intention to simulate the application of a turbocharger as the boosting system in the present tests.

\section{Fuel injection system}

For the fuel injection, a direct injection system with a solenoid injector and an externally driven gasoline pump have been selected. As seen in the table, this system will work with an injection pressure of 150 bar. And two different injection strategies are going to be defined. The first one, with an injection splitted in two events: an initial pre-injection during the NVO period (exhaust gases recompression), in which a small portion of the total fuel amount per cycle is injected, and the main injection, placed as soon as possible to maximize the fuel homogenization inside the cylinder (Figure 3, top). And the second strategy will be a single injection event, so that the pre-injection during the recompression will be removed.

The initial strategy has been selected to get better conditions for the CAI operation, increasing the charge reactivity through the initial pre-injection during the recompression stroke ${ }^{31}$, and in the second case, in order to evaluate the performance of the combustion without that preinjection.

Along the different tests, the engine load degree is going to be modified, increasing it progressively until the maximum achievable. For each test the IMEP will be fixed on a value, and the fuel amount will be adjusted to keep this value constant. As there are two fuel injection strategies, in the case of the splitted injection, the pre-injection has been kept 


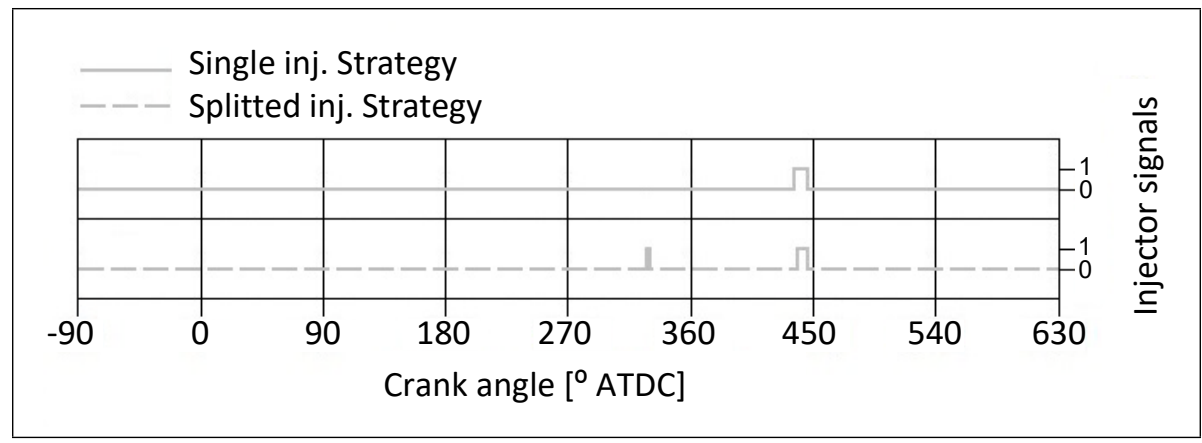

Figure 3. Fuel injection strategies.

constant and the DOI (Duration Of Injection) of the main injection has been modified to adjust the fuel amount keeping the EOI (End Of Injection) constant. And in the case of the single injection strategy, the strategy is essentially the same but without the pre-injection.

\section{Water injection system}

For confidentiality reasons, only a few qualitative data of the water injection system will be given. This one is a DI system, and it works with distilled water. The amount of water injected per cycle is calculated from the mass flow rate measured in a gravimetric balance. Once the amount of injected water is determined, the ratio between the water and the injected fuel (water/fuel ratio) will be computed, which will be the parameter used to define the water addition in each given test.

The water injection pressure is fixed at 100 bar, based on a previous optimization ${ }^{30}$. If this value is increased from lower values, the engine operation showed to be improved until reaching 100 bar injection pressure. The knock intensity and the maximum pressure rise rates $\left(\mathrm{dP}_{\max }\right)$ were reduced, and the combustion efficiency and stability were improved. However, when the injection pressure was further increased, this improvement did not continue. Besides, higher injection pressures lead to other troubles, as difficulties to reduce the water amount injected per stroke, more energy requirements and an increase of the risk of water-oil dilution.

\section{Methodology}

Along this subsection, the works performed, the test plan, the most important operating boundaries, the measurement procedures, and the key aspects to understand the work presented in this paper are going to be summarized and explained.

The works performed have followed these steps:

- Overview of the water effect on the CAI combustion (Review of the results of the previous work ${ }^{30}$ ).

- Modification of the engine compression ratio (CR) to a value more commonly used for automotive purposes in SI engines.

- Study of different fuel injection strategies and their interaction with water injection for controlling the combustion.

- Analysis of the effect of the engine speed modification over all the strategies mentioned in the previous steps.

The test plan has been to increase progressively the load degree for each engine configuration in order to find the maximum load degree along the different cases of study. During this work, each individual test shown has followed a previous optimization process in order to search for the best results, and then the main work has continued following the optimal operating strategies.

The main operating boundaries during this work are described in the following lines: 
- Intake temperature: as already known, when the engine is operated with CAI combustion, the temperature of the intake gases is very important as it modifies the mixture reactivity. This temperature has been kept constant at $50^{\circ} \mathrm{C}$ for all the tests.

- Maximum pressure rise rate $\left(\mathrm{dP}_{\max }\right)$ : the combustion speeds are very fast under CAI conditions, leading to very high pressure rise values, which if not controlled, can damage the engine. The maximum value depends on the engine structure and materials. In this case, the limit has been set at $10 \mathrm{bar} / \mathrm{CA}$. If this value is overpassed, the operation is considered dangerous and the test is stopped.

- Combustion stability ( $\sigma$ IMEP): this parameter is very important since an unstable combustion leads to lots of misfires and a loss in the necessary reactivity to keep a constant CAI combustion. To evaluate this parameter, the standard deviation of the IMEP is used, and a threshold of 0.15 bar is defined as the maximum deviation for CAI combustion, following the same criteria as in previous works ${ }^{30}$.

- The combustion knock: the knock characterization is defined by the MAPO (Maximum Amplitude of Pressure Oscillations). This value is obtained from the high frequencies of the in-cylinder pressure signal, and the maximum value of the corresponding amplitude at each cycle is taken ${ }^{32}$. For this work, a MAPO value of 3 bar is considered as light knock (i.e. few cycles with this knock value are allowable) and for values of 6 bar or more, are considered as hard knock, and thus not permitted.

Regarding the measurement of the different tests performed, two types of data are recorded: instantaneous and averaged parameters. The instantaneous data is obtained thanks to the fast pressure measurements, measuring 150 combustion cycles during each test, and after that calculating the averaged pressure cycle to obtain the heat release law and the rest of combustion-related parameters by a heat release analysis ${ }^{33}$. And the averaged data, is the result of averaging a measurement during $30 \mathrm{~s}$ from the signals with less temporary resolution, as temperatures or mass flows.

And finally, through this paper the graphs layout shown in the Figure 4, has been defined as a standard to present the different results along the document. Inside the figure, different plots are shown in order to give the most relevant information in a condensed way. The $\mathrm{X}$ axis is common for all the plots, and the title of each plot shows the Y axis. Each individual dot presented is the corresponding measured or calculated data, all of them linked with lines to highlight the trends of the different parameters shown. Finally, on the plot were the knock results are presented, there is a singularity: the dots and the corresponding line are not coincident. This is because in this plot there are two informations: the dots are representative of the maximum measured MAPO and the line represents the average of the measured MAPO during all the test.

\section{Results and discussion}

\section{Water injection in CAl conditions}

The works performed about water injection have shown the potential of this methodology to increase the maximum achievable load at CAI conditions. By this way the advantages (low pollutant emissions and better efficiency) of this singular combustion mode are able to be used in a higher operation range.

The starting point is a small search of the maximum achievable load without water on CAI conditions already presented in $^{30}$, and the corresponding results are shown in Figure 4 (black data). The obtained result shows that from 3.5 bar IMEP, the knock, $\mathrm{dP}_{\max }$ and $\sigma \mathrm{IMEP}$ were out of the acceptable limits, and consequently the CAI operation without water injection was constrained. If water was added 


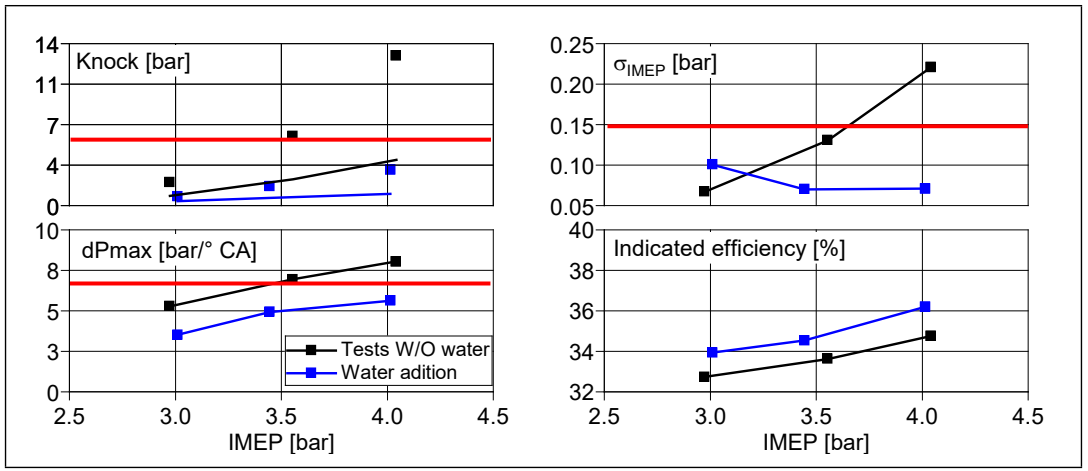

Figure 4. Initial results of the effect of water injection $-\mathrm{CR}=14.7$, splitted fuel injection and $1500 \mathrm{rpm}-$. Source: Valero-Marco et al. ${ }^{30}$

(blue data), the results reveal a noteworthy improvement that allows to further increase the load degree. The in-cylinder charge reactivity is reduced, and thus knock and $\mathrm{dP}_{\max }$ are located inside acceptable limits.

Water injection has allowed the increase of the engine load, and the results of this increase are presented in Figure 5. This evolution has been achieved through a progressive increment of the amount of injected water to keep the combustion inside the established boundaries. For the results shown in the figure, the engine configuration was as follows: compression ratio of 14.7 , engine speed of $1500 \mathrm{rpm}$ and split fuel injection strategy. At the same time, it may be reminded that the other settings employed to control the combustion have also been optimized at each load level to get the better efficiency. These are: the NVO, the intake pressure, the water amount and the Start Of Injection (SOI) of the water. This optimization process is further dealt with in the already mentioned previous part of this work ${ }^{30}$.

If the combustion parameters are observed, a delay of the combustion phasing and an increase in the combustion duration with the increase of the engine load can be seen. The increase of the combustion duration is caused by the necessary reduction of the mixture reactivity to keep the combustion inside acceptable knock and $\mathrm{dP}_{\max }$ limits. Then, the combustion phasing (CA50) has been delayed progressively, mainly due to the combustion duration increase. But if the combustion onset is reviewed in Figure 6, the start of the combustion has remained almost constant (1.25 $\mathrm{CA}$ difference between 5 and 10 bar IMEP).

The indicated efficiency has been around $40 \%$ in all loads. However, there is a slight and progressive increase of the efficiency as the engine load is increased, until the 10 bar IMEP are reached. This was the maximum load achieved inside the limits defined for these tests.

Once the results of the load variation in CAI conditions have been seen, the different trends of each engine operating setting can be analyzed.

- First, the NVO has to be reduced progressively with the increase of the load, this means that the amount of hot residual gases has to be reduced. This is necessary to reduce the mixture reactivity, since the trapped mass inside the cylinder is higher, and so does the pressure and temperature of the charge (higher reactivity).

- Second, the optimum value for the air/fuel ratio is around lambda 1.75 for all the points. Theoretically, the leaner the mixture, the higher the efficiency. But with an excessive increase of the lambda, the combustion stability is worsened, and finally a value of lambda of around 1.75 seems to be the appropriate compromise. In addition, to keep the air excess around that value, the intake pressure needs to be progressively increased.

- Third, the required water amount has increased quickly, becoming necessary an amount of 1.5 times 


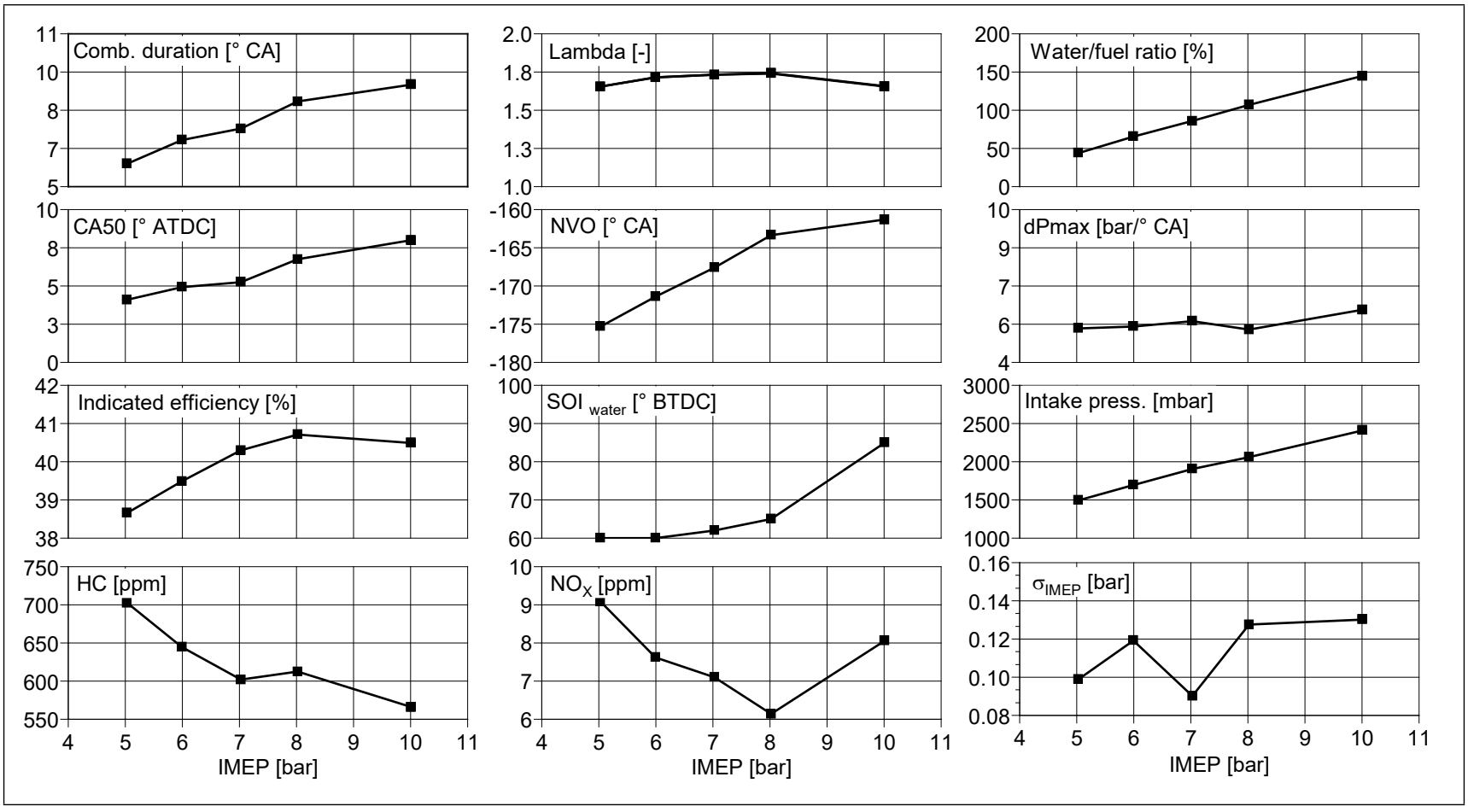

Figure 5. Load variation for an engine configuration of $C R=14.7$ and a split fuel injection strategy.

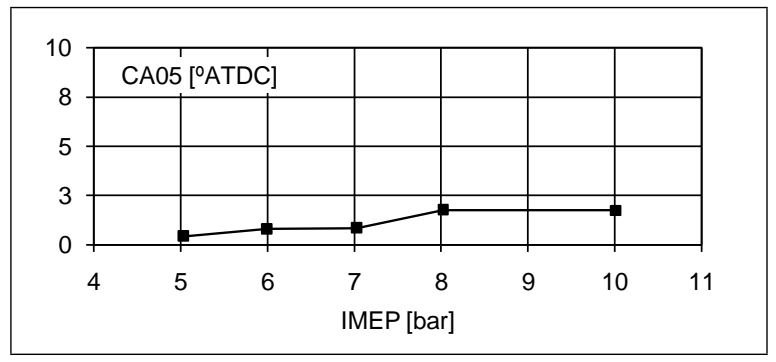

Figure 6. Combustion onset of the load variation ( $C R=14.7$ and a split fuel injection strategy).

the gasoline mass flow at the highest load achieved (10 bar IMEP) to reduce the excessive pressure gradients. Regarding the SOI of the water injection, this has been progressively advanced because the higher amount of water needs higher injection duration and more time for evaporation. In this case, the trend is nonlinear because the amount of water also increases nonlinearly: (1) the water/fuel ratio increases with the engine load, and (2) the fuel mass flow also increases with the engine load.

And finally, regarding the pollutant emissions at these test sets. The unburned hydrocarbons follow a decreasing trend with the increase of the engine load (which is a common result in SI engines) ${ }^{34}$, and the $\mathrm{NO}_{x}$ emissions are really low for all loads. So, the application of this strategy, as can be seen, does not have a detrimental effect on emissions.

\section{Influence of the compression ratio and fuel}

\section{injection strategy}

Based on the above tests, some questions arise: what happens if the compression ratio is reduced?, and what happens if the injection is set by removing the pre-injection during the recompression stroke? This decision is motivated by the results already obtained, where it has been observed that there was enough reactivity, even an excess in some cases, since combustion was generally too advanced and the engine needed a large amount of water to operate correctly.

The fact of changing these two specifications in the engine leads to very different conditions for the combustion process. The lower pressures and temperatures reached at TDC (associated to the lower CR) and the elimination of the fuel pre-injection should lead to a decrease in mixture reactivity. Therefore, it is necessary to see how these changes 
affect the combustion process and redefine which is the maximum achievable load without water injection now.

The results obtained with this new engine configuration are shown in Figure 7, and it is observed that the maximum achievable load without water injection is significantly higher (around 50\% higher compared to the previous configuration). This proves the big influence of these two parameters on the CAI combustion, where the reactivity has to be managed continuously.

To understand the effects of both modifications separately, different tests have been carried out. In a first step, the CR has been compared with other previously measured tests set using the same fuel injection strategy than the one used before (dual injection).

Figure 8 shows two test sets with the two different compression ratios. Both test sets have been performed at 5 bar IMEP with the same NVO configuration. The combustion phasing has been modified to different crank angle positions through the modification of the amount of water injected. As it can be seen, a greater amount of water is needed to get the same combustion phasing with a higher CR (27.5\% more water in average), even with a slightly higher air/fuel ratio (the higher the air/fuel ratio, the lower the temperature).

Therefore, the effect of an increment in compression ratio, as expected, increases the efficiency and the mixture reactivity, since the achieved levels of pressure (and, therefore, temperature) at the end of the compression stroke are higher.

Regarding emissions, the $\mathrm{NO}_{x}$ emissions have been shown to be smaller with the higher CR. This result shows that the water effect is stronger than the $\mathrm{CR}$ increase. This is also consistent with the $\mathrm{HC}$ emissions because these have increased with the higher amount of water injected. The understanding of these two trends can be related to the reactivity management, since this has to be decreased, leading to a cooler mixture.
Now that the effect of the CR modification is already known the lower CR configuration has been retained, and the effects of the different fuel injection strategies are going to be analyzed (Figure 9).

With the single injection strategy the reactivity of the mixture is lower, since there is no fuel injection during the recompression of the exhaust gases. Therefore, the amount of water needed is lower. Additionally, this lower reactivity of the mixture makes it necessary to increase the NVO, getting lower lambda values for the same intake pressure and higher pumping losses.

The resulting combustion phasing for the single injection case has shown to be better. For this engine, the combustion phasing target has been set to $8^{\circ} \mathrm{CA}$ in order to optimize the fuel efficiency, and this has been achieved thanks to the lower previous in-cylinder reactivity and the settings of the rest of parameters (e.g. water injection, NVO). This statement is in agreement with Caton ${ }^{35}$, who determined also that the optimal combustion phasing should be in between 5 and $10^{\circ}$ ATDC to optimize the fuel efficiency. Therefore, this change in injection strategy should lead to a higher efficiency. This is not the case at low loads, because the lambda of the single injection case is much lower to get the engine running. But this is the case for medium loads, where the lambda is similar for both injection strategies. However, the benefit found at medium loads does not remain at higher loads, and at 10 bar IMEP the indicated efficiency decreases. At these conditions, the required amount of water starts to increase, and thus the combustion is more delayed.

The maximum load limit of 10 bar IMEP cannot be surpassed with the modification of the injection strategy, since the combustion stability is worsened with the single injection strategy, also explaining why the efficiency decreases (Figure 9).

The $\mathrm{NO}_{x}$ trend does not give any special information about the best injection strategy. Taking as a reference the best efficiency tests for each load, independently of the 


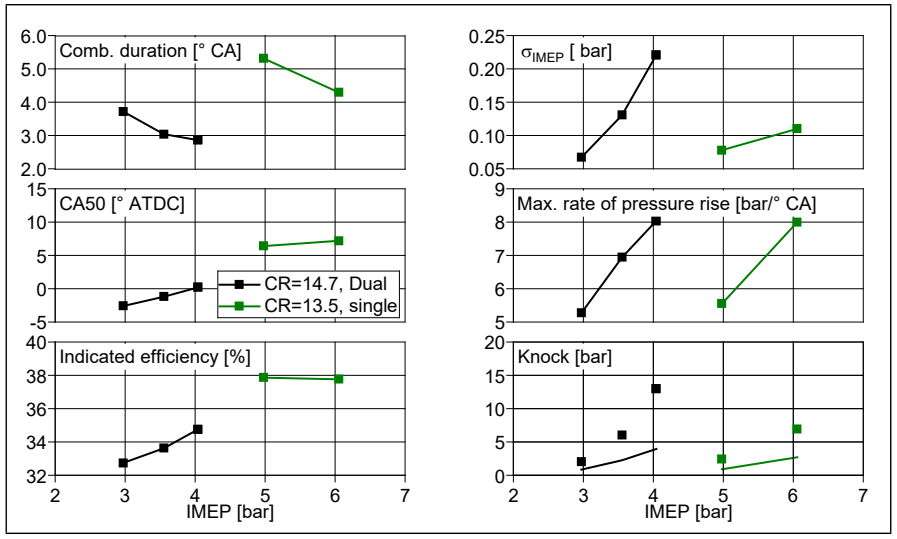

Figure 7. Maximum load without water for both engine configurations.

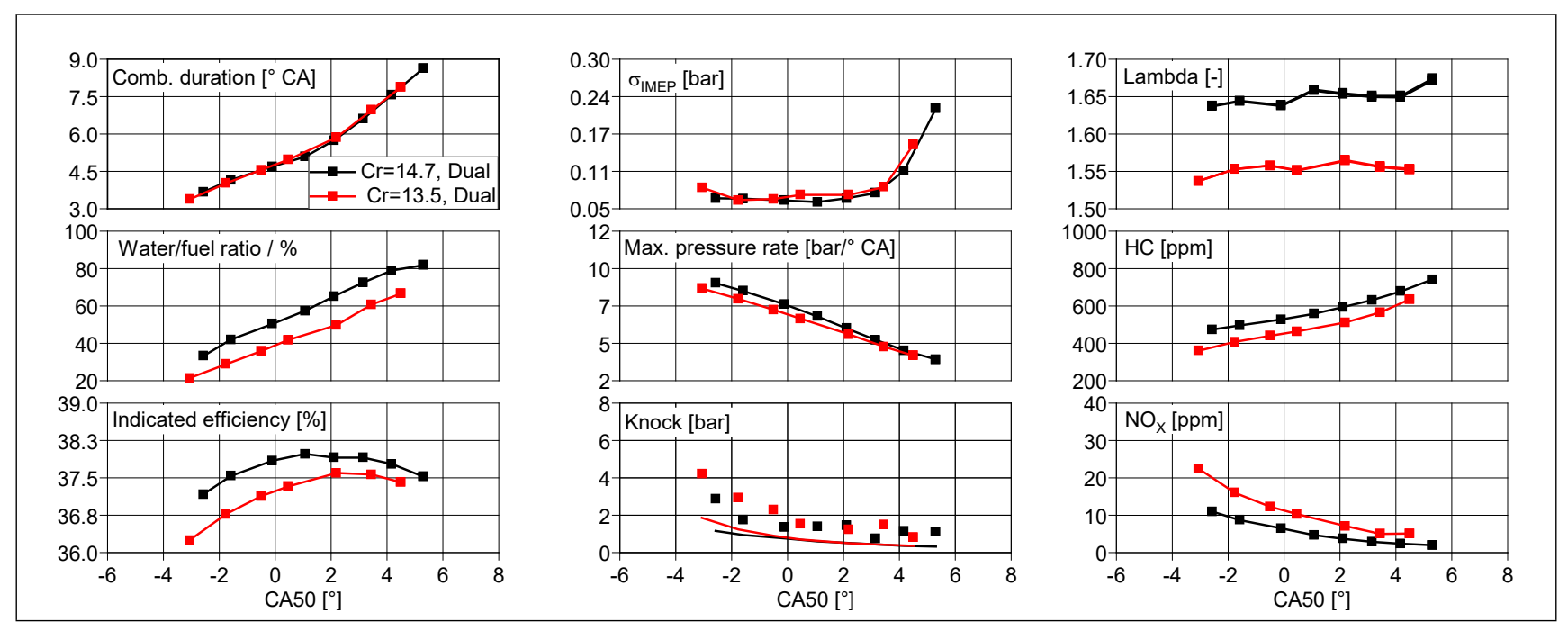

Figure 8. CA50 variation test at 5 bar constant load.

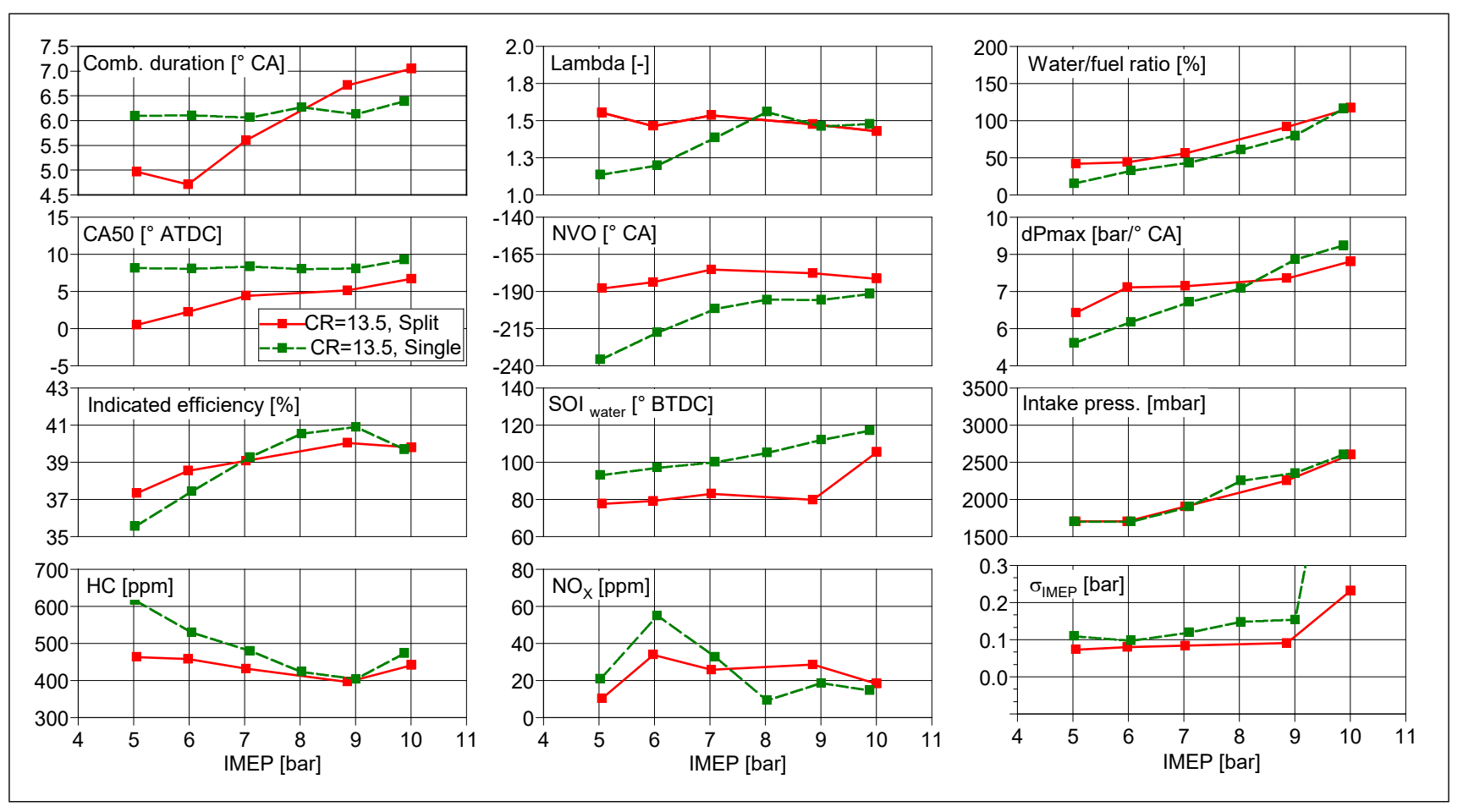

Figure 9. Load variation for both injection strategies, split and single. 
injection strategy, $\mathrm{NO}_{x}$ are lower for the case having the best indicated efficiency, and consequently lower for the split injection cases at low load, and for the single injection cases at medium and high loads (it has to be reminded that these emissions are very low during CAI operation, as it can be seen in the values obtained; apart from that, a singular point can be seen, where the $\mathrm{NO}_{x}$ emissions seem to increase; however, this is just an indication that a further optimization process of the operating strategies should be performed to remove these singular discrepancies). And regarding $\mathrm{HC}$ emissions, the trend is the same as in Figure 5: they decrease with the engine load. The 10 bar IMEP tests are an exception to this trend, due to the $\sigma \mathrm{IMEP}$ worsening.

Based on these results, the better fuel injection strategy depends on the engine load. At low engine loads, split injections are more interesting, since a better efficiency is obtained thanks to a greater reactivity of the mixture, which makes easier the combustion. As far as the engine load is increased, the mixture is reactive enough and the preinjection starts to be unnecessary, giving an over-advanced combustion phasing and worsening the indicated efficiency. Consequently, in this latter situation, a single injection strategy is more suitable.

\section{Engine speed modification}

When the engine speed is modified, the combustion conditions are also altered. An increase in speed makes the engine more adiabatic, meaning that the heat losses are reduced. Besides, there is less time available to carry out the scavenging, homogenization and combustion processes. And, finally, the gas dynamics is also modified. This makes necessary to explore how the modification of the engine speed affects the CAI conditions, so as to adapt the different operation strategies depending on the engine speed (managing the operating settings to get an optimum performance).
For this case study, the initial engine speed of $1500 \mathrm{rpm}$ has been increased up to $2000 \mathrm{rpm}$. The chosen injection strategy has been the initial one (split), and both studies have been performed with a compression ratio of 13.5 . For the higher engine speed case the fuel pre-injection has remained constant and the main injection has been advanced $20^{\circ} \mathrm{CA}$.

Once the required tests to perform a load variation at different engine speeds (Figure 10) have been performed, it is possible to see that:

- The efficiency is generally higher.

- The necessary hot residual gases is lower.

- The obtained operation range is slightly wider for $2000 \mathrm{rpm}$.

- The combustion durations are very similar in terms of ${ }^{\circ} \mathrm{CA}$ in both speeds, which means that the combustion speed in terms of time has been increased with the engine speed (since the combustion propagation mechanisms here are different than the SI, a further analysis on the reactivity to separate the different effects here would be necessary).

- The combustion phasing, except for the first points, is slightly delayed with respect to the case at $1500 \mathrm{rpm}$.

The CAI operation at $2000 \mathrm{rpm}$ has been shown to reach higher efficiencies, since the necessary hot residual rates are lower and therefore the points can be operated with higher lambdas. The engine operating settings have changed with regard to the tests at $1500 \mathrm{rpm}$, the NVO values have been reduced, leading to those lower residual rates, lower pumping loses and an intake pressure reduction thanks to a higher engine permeability.

With regard to the water injection, the amount to be injected has been shown to be lower compared to the $1500 \mathrm{rpm}$ case to get similar conditions (30\% less water in average) thanks to the lower NVO values and probably the lower residence time of the charge inside the cylinder before combustion. However, it can be pointed out that the same 


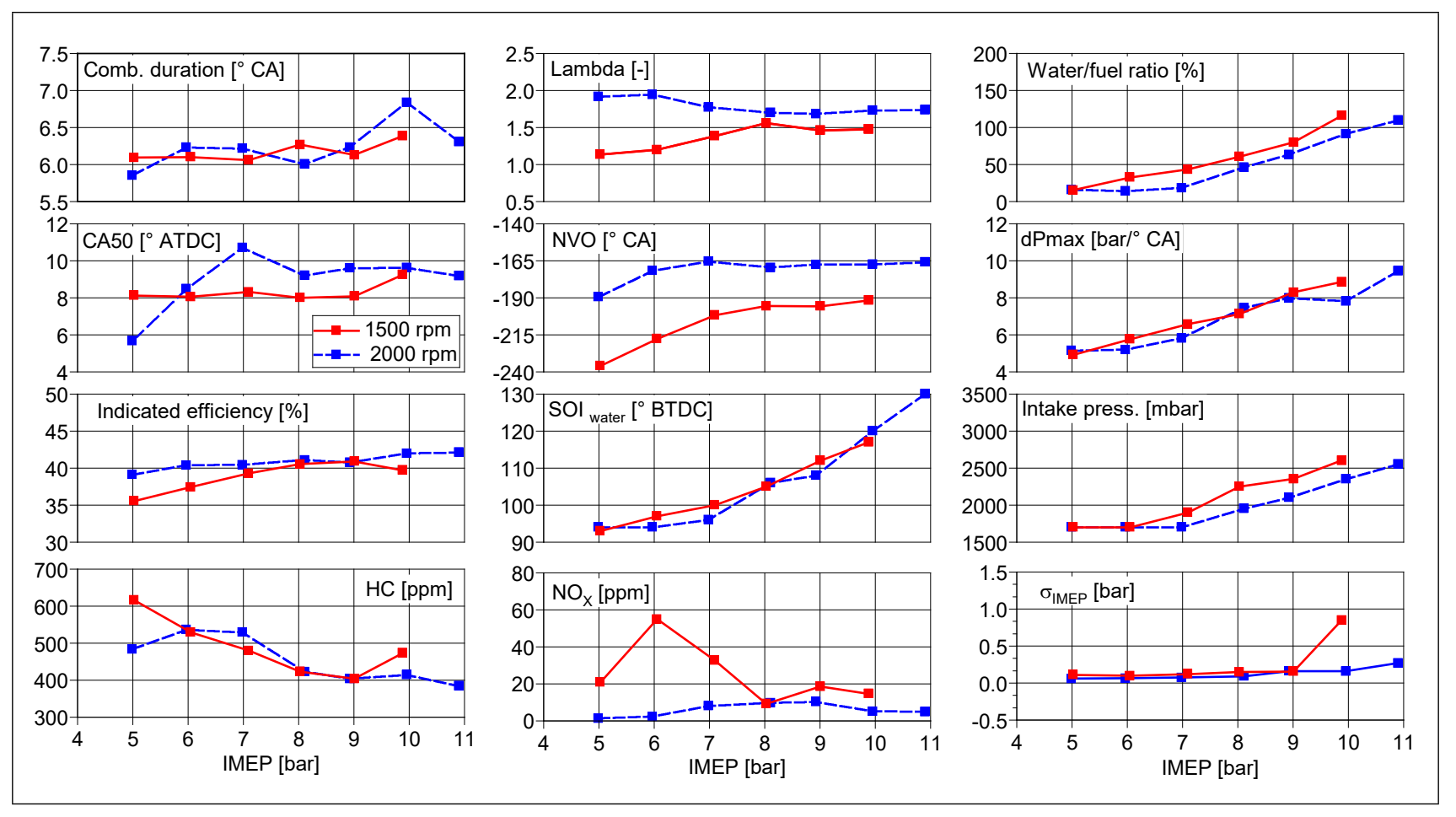

Figure 10. Load variation for different engine speeds (Split injection and $C R=13.5$ ).

SOI angle as in the previous engine speed is used. This is because, on the one hand, the amount of water is smaller (this means less time required to evaporate) and, on the other hand, the engine has a higher angular speed (less time per stroke). In this particular case both effects are balanced, resulting in the same SOI. However, for other engine speeds it would be necessary to evaluate the time required for the water homogenization, since the present results might not be always applicable.

The HC emissions follow the same trends explained previously, and the $\mathrm{NO}_{x}$ emissions have decreased with the increase in engine speed. The interpretation of all these results indicates that the smaller required reactivity leads to lower necessary residual rates and higher lambdas during the combustion process, thus helping to reduce even more $\mathrm{NO}_{x}$ emissions.

\section{Conclusions}

All through this work, different engine configurations to operate a CAI combustion system have been studied, aiming at increasing the available information about how the feasibility and the methodology to manage high loads with water addition can be achieved.

\section{- Summary of the use of water injection under}

CAI combustion conditions. Water injection has demonstrated to be an effective solution to reduce the excessive charge reactivity during the engine operation in CAI conditions. Thanks to its higher specific heat capacity, the temperatures of the airfuel mixture during the compression stroke and the combustion can be reduced, leading to a reduction of the combustion speeds and delaying the combustion position. These changes lead to a better control of the pressure rise rates and the knock intensity, nevertheless the combustion stability can be worsened, since the incylinder charge reactivity is reduced. The comparison of the achievable load increase without and with water injection for the initial engine configuration have shown an increase from 3.5 bar to 10 bar IMEP maximum achievable load degree. This means an improvement of almost three times $(\uparrow 185 \%)$ of the 
maximum load degree achievable in CAI conditions. Regarding the required amount of water for each load, this has been shown to be variable: with the load degree increase, the water requirement increases up to 1.5 times the amount of fuel injected. And regarding the emissions, this strategy has been shown that it does not worsen the pollutant emissions. Nevertheless, the increase of the load increases the difficulties to find a stable operating point within the defined boundaries, since the possibilities to control the $\sigma$ IMEP, the knock and the $\mathrm{dP}_{\text {max }}$ are narrower.

- Effect of the compression ratio. The compression ratio influences the pressure and temperature at the end of the compression stroke, thus directly affecting the mixture reactivity. The increase of this parameter makes necessary a higher amount of water to control the $\mathrm{dP}_{\max }$ and knock. Based on the results shown in Figure 8 , a $27.5 \%$ more water in average has been necessary to increase it from 13.5 to 14.7 .

- Effect of the fuel injection strategy modification. The fuel injection strategy has a significant influence on the reactivity of the mixture and the combustion performance, thus affecting the required amount of water to optimize the engine operation. According to the results, the fuel pre-injection during the recompression stroke used to ensure the CAI combustion has been shown not to be strictly necessary. Nevertheless, the most suitable injection strategy has been shown to be dependent on the engine load. Split injections are the best solution for low loads since the combustion is more stable and efficient, but as the engine load is increased, the excessive mixture reactivity can be reduced changing to a single injection strategy, which is now more appropriate. Anyway, the water injection can not be avoided with the optimization of these parameters.
- Increased engine speed. The obtained results for an increase in engine speed from 1500 to $2000 \mathrm{rpm}$ have shown that the necessary charge reactivity is lower to run the engine in CAI conditions when the speed is increased. The necessary NVO values are lower, and the engine can be operated at higher lambdas. Due to these changes, first, the engine shows better indicated efficiency and an improved combustion stability, and second, the required water amount is smaller (30\% less water in average) and the CAI range can be enlarged compared to the results at lower engine speeds. These results indicate that the increase of the engine speed helps also the management of this combustion mode.

\section{Future directions}

This work could take two possible directions:

Full map operation scenario:

To achieve an engine able to operate under CAI combustion in the whole operating map, more research work is necessary. If the present work is continued, an important topic would be the way to reduce the water consumption by means of further optimization of the hardware and the operating strategies. The increase of the engine speed has shown good results, but needs to be further analyzed with data at more speeds. And regarding the CR, a Variable Compression Ratio system could be a very interesting solution to deal with the engine reactivity, to optimize the necessary amount of water, and to explore the different achievable load degrees.

\section{Partial operation scenario:}

This kind of engines could be a good option to implement them as range extenders for hybrid powertrains, since the engine operation is constricted to a few steady-state operating points. In this case, if these operating points are kept inside the CAI operating range, the emitted pollutants would be very low compared to a standard SI engine, the efficiency would be higher, and with the help of the water, 
the output power could be increased. In this direction, the engine configuration could be defined in view of the results presented here to optimize the engine design.

\section{Acknowledgements}

This research work was part of the Research Unit (Forschergruppe) FOR 2401 "Optimization based Multiscale Control for Low Temperature Combustion Engines", funded by the German Research Association (Deutsche Forschungsgemeinschaft, DFG). The support for this research is gratefully acknowledged. The authors would also like to thank the different members of the VKA institute for combustion engines (RWTH Aachen university) and CMT-Motores Térmicos (Universitat Politècnica de València), directly or indirectly involved in this work, for their contribution. And finally, regarding the funding of the $\mathrm{PhD}$. studies of Jorge Valero-Marco, we would like to thank also the Universitat Politècnica de València (contract 3102) for its support.

\section{Notation}

$\begin{array}{ll}B D C & \text { Bottom Dead Center } \\ C A & \text { Crank Angle } \\ C A 05 & \text { Crank Angle where } 5 \% \text { of the fuel mass } \\ & \text { has been burned } \\ C A 50 & \text { Crank Angle where 50\% of the fuel mass } \\ C A I & \text { has been burned } \\ C I & \text { Controlled Autoignition } \\ C R & \text { Compression Ratio } \\ D I & \text { Direct Injection } \\ d P_{\text {max }} & \text { Maximum pressure rise rate } \\ E G R & \text { Exhaust Gas Recirculation } \\ E O I & \text { End Of Injection } \\ E V C & \text { Exhaust Valve Closing } \\ E V O & \text { Exhaust Valve Opening } \\ & \end{array}$

\section{GCAI Gasoline CAI}

HCCI Homogeneous Charge Compression Ignition

IMEP Indicated Mean Effective Pressure

IVC Intake Valve Closing

IVO Intake Valve Opening

MAPO Maximum Amplitude of Pressure Oscillations

$N O_{x} \quad$ Nitrogen Oxides

NVO Negative Valve Overlap

SI Spark Ignition

SOI Start Of Injection

$\sigma I M E P \quad$ Standard deviation of the IMEP

RON Research Octane Number

SOI Start Of Injection

TDC Top Dead Center

VVT Variable Valve Timing

\section{References}

1. Onishi S, Jo SH, Shoda K, Jo PD, Kato S. Active ThermoAtmosphere Combustion (ATAC) - A new combustion process for internal combustion engines. SAE Technical Papers. 1979;(790501).

2. Noguchi M, Tanaka Y, Tanaka T, Takeuchi Y. A study on gasoline engine combustion by observation of intermediate reactive products during combustion. SAE Technical Papers. 1979;(790840)

3. Curran HJ, Pitz WJ, Westbrook CK, Callahan CV, Dryer FL. Oxidation of automotive primary reference fuels at elevated pressures. Symposium (International) on Combustion. 1998;27(1):379-387.

4. Tanaka S, Ayala F, Keck JC, Heywood JB. Two-stage ignition in HCCI combustion and HCCI control by fuels and additives. Combustion and Flame. 2003;132(1-2):219-239.

5. Zhao H. HCCI and CAI engines for the automotive industry. Woodhead Publishing in mechanical engineering. Elsevier Science; 2007. 
6. Zhang Y, Zhao H. Investigation of combustion, performance and emission characteristics of 2-stroke and 4-stroke spark ignition and $\mathrm{CAI} / \mathrm{HCCI}$ operations in a DI gasoline. Applied Energy. 2014;130:244-255.

7. Osbourne RJ, Li G, Sapsford SM, Stokes J, Lake TH, Heikal MR. Evaluation of HCCI for Future Gasoline Powertrains. SAE Technical Papers. 2003;(2003-01-0750).

8. Onishi S, Jo SH, Shoda K, Jo PD, Kato S. Active ThermoAtmosphere Combustion (ATAC) - A new combustion process for internal combustion engines. SAE Technical Papers. 1979;(790501).

9. Zhao H, Peng Z, Ladommatos N. Understanding of controlled autoignition combustion in a four-stroke gasoline engine. Proceedings of the Institution of Mechanical Engineers, Part D: Journal of Automobile Engineering. 2001;215(12):1297-1310.

10. Cinar C, Uyumaz A, Solmaz H, Sahin F, Polat S, Yilmaz E. Effects of intake air temperature on combustion, performance and emission characteristics of a HCCI engine fueled with the blends of 20n-heptane and 80 Fuel Processing Technology. $2015 ; 130(\mathrm{C}): 275-281$.

11. Uyumaz A. An experimental investigation into combustion and performance characteristics of an HCCI gasoline engine fueled with n-heptane, isopropanol and n-butanol fuel blends at different inlet air temperatures. Energy Conversion and Management. 2015;98:199-207.

12. Lee K, Cho S, Kim N, Min K. A study on combustion control and operating range expansion of gasoline HCCI. Energy. 2015;91:1038-1048.

13. Jang J, Lee Y, Cho C, Woo Y, Bae C. Improvement of DME HCCI engine combustion by direct injection and EGR. Fuel. 2013;113:617-624.

14. Dahl D, Denbratt I. HCCI/SCCI load limits and stoichiometric operation in a multicylinder naturally aspirated spark ignition engine operated on gasoline and E85. International Journal of Engine Research. 2011;12(1):58-68.

15. Caton PA, Song HH, Kaahaaina NB, Edwards CF. Residualeffected homogeneous charge compression ignition with delayed intake-valve closing at elevated compression ratio. International Journal of Engine Research. 2005;6(4):399-419.

16. Yang J. Expanding the operating range of homogeneous charge compression ignition-spark ignition dual-mode engines in the homogeneous charge compression ignition mode. International Journal of Engine Research. 2005;6(4):279-288.

17. Yoshizawa K, Teraji A, Miyakubo H, Yamaguchi K, Urushihara T. Study of high load operation limit expansion for gasoline compression ignition engines. Journal of Engineering for Gas Turbines and Power. 2006;128(2):377-387.

18. Li Y, Zhao H, Brouzos N, Leach B. Managing controlled auto-ignition combustion by injection on a direct-injection gasoline engine. Proceedings of the Institution of Mechanical Engineers, Part D: Journal of Automobile Engineering. 2007;221(9):1125-1137.

19. Xu HM, Wyszynski ML, Megaritis A, Yap D, Wilson T, Qiao $\mathrm{J}$, et al. Research on expansion of operating windows of controlled homogeneous auto-ignition engines. International Journal of Engine Research. 2007;8(1):29-40.

20. Ogawa H, Miyamoto N, Kaneko N, Ando H. Combustion control and operating range expansion with direct injection of reaction suppressors in a premixed DME HCCI engine. SAE Technical Papers. 2003;(2003-01-0746).

21. Dempsey AB, Das Adhikary B, Viswanathan S, Reitz RD. Reactivity controlled compression ignition using premixed hydrated ethanol and direct injection diesel. Journal of Engineering for Gas Turbines and Power. 2012;134(8).

22. Megaritis A, Yap D, Wyszynski ML. Effect of water blending on bioethanol HCCI combustion with forced induction and residual gas trapping. Energy. 2007;32(12):2396-2400.

23. Kaneko N, Ando H, Ogawa H, Miyamoto N. Expansion of the operating range with in-cylinder water injection in a premixed charge compression ignition engine. SAE Technical Papers. 2002;(2002-01-1743).

24. Iwashiro Y, Tsurushima T, Nishijima Y, Asaumi Y, Aoyagi Y. Fuel consumption improvement and operation range expansion in HCCI by direct water injection. SAE Technical Papers. 
2002;(2002-01-0105)

25. Christensen M, Johansson B. Homogeneous charge compression ignition with water injection. SAE Technical Papers. 1999;(1999-01-0182).

26. Golzari R, Zhao H, Hall J, Bassett M, Williams J, Pearson R. Impact of intake port injection of water on boosted downsized gasoline direct injection engine combustion, efficiency and emissions. International Journal of Engine Research. 2019;.

27. Hoppe F, Thewes M, Baumgarten H, Dohmen J. Water injection for gasoline engines: Potentials, challenges, and solutions. International Journal of Engine Research. 2016;17(1):86-96.

28. Li A, Zheng Z, Peng T. Effect of water injection on the knock, combustion, and emissions of a direct injection gasoline engine. Fuel. 2020;268.

29. Schmitt S, Wick M, Wouters C, Ruwe L, Graf I, Andert J, et al. Effects of water addition on the combustion of iso-octane investigated in laminar flames, low-temperature reactors, and an HCCI engine. Combustion and Flame. 2020;212:433-447.

30. Valero-Marco J, Lehrheuer B, López JJ, Pischinger S. Potential of water direct injection in a $\mathrm{CAI} / \mathrm{HCCI}$ gasoline engine to extend the operating range towards higher loads. Fuel $2018 ; 231: 317-327$.

31. Tongroon M, Zhao H. Thermal and chemical effects of fuel direct injection on kinetically controlled combustion of alcohol and gasoline fuels. International Journal of Engine Research. 2015;16(8):982-993.

32. Zhen X, Wang Y, Xu S, Zhu Y, Tao C, Xu T, et al. The engine knock analysis - An overview. Applied Energy. 2012;92:628636.

33. Heywood J. Internal combustion engine fundamentals. McGraw-Hill; 1988.

34. Zhao H, Li J, Ma T, Ladommatos N. Performance and analysis of a 4-stroke multi-cylinder gasoline engine with CAI combustion. SAE Technical Papers. 2002;(2002-01-0420).

35. Caton JA. Combustion phasing for maximum effciency for conventional and high effciency engines. Energy Conversion and Management. January 2014;77:564-576. 